\title{
Load Distribution Characteristics of Surrounding Rock for Double-arch Tunnel Considering Pressure-arch Effect
}

\author{
Chunliu Li ${ }^{1,2, *}$, Hao Liu ${ }^{1}$, Shuangjun $\mathrm{Xu}^{1}$, Jingtao $\mathrm{Li}^{2}$ and Chenhua Zhou \\ ${ }^{1}$ Institute of Urban Construction, Hebei Normal University of Science \& Technology, Qinhuangdao 066004, China \\ ${ }^{2}$ International Joint Research Laboratory of Henan Province for Underground Space Development and Disaster Prevention, \\ Henan Polytechnic University, Jiaozuo 454003, China \\ ${ }^{3}$ School of Civil Engineering and Architecture, Northeast Electric Power University, Jilin 132012, China
}

Received 28 September 2019; Accepted 12 February 2020

\begin{abstract}
Aiming at the insufficiency of the formula for calculating the vertical load of the surrounding rock of the double-arched tunnel, based on the Terzaghi theory and considering the pressure-arch effect, a mechanical model of the surrounding rock of the single-arched and double-arched tunnel was constructed. The formula for calculating the vertical stress in pressure-arch effect zone was deduced, and the calculating method for the double-arch tunnel with different distribution forms of pressure-arch was discussed. Taking the typical double-arch tunnel on a highway, the distribution characteristics of pressure-arch in the surrounding rock after single-arch and double-arch tunnels excavation were analyzed by using FLAC3D technique. Results show that the skewness pressure-arch effect exists in the surrounding rock after the doublearch tunnel excavation, the distribution range and peak value of arching index of the pressure-arch are relatively higher in the first excavated tunnel. The distribution of the vertical stress at the top of the double-arch tunnel is asymmetric, and the vertical stress in the pressure-arch effect zone decreases gradually from the left boundary to the mid-span along the horizontal direction. The obtained conclusions provide a basis for the load calculation of the surrounding rock of the double-arch tunnel.
\end{abstract}

Keywords: Double-arch tunnel, pressure-arch, skewness effect, surrounding rock

\section{Introduction}

The double-arch tunnel is a typical large-span tunnel structure composed of two independent precast arches. It has the advantages of less area and high space utilization. With the increase of the transportation construction in the world, this tunnel is widely used in railway, highway and subway engineering [1-2].

However, the double-arch tunnel need many construction procedures and its surrounding rock often bears complicated forces, the mid-partition wall usually supports the left and right tunnels. There is the frequent stress conversion occurring between the surrounding rock and the partition wall under the step-by-step excavation disturbance, which load pattern is different from the single-arch tunnel [3]. Some double-arched tunnels suffered from structural cracking after construction, in addition to the impact of the construction technology and construction quality, the surrounding rock load is a key factor affecting the stability of the lining structure [4]. The weight of the overlying soil on a deep-buried tunnel structure is generally considered as a uniform load, and the overlying soil load adjacent to the tunnel shows an arching phenomenon. Under the influence of the arch effect, the average supporting force will be higher or lower than the self-weight load of the overlying soil [5].

Since there is the interaction of pressure-arches in the surrounding rock between both sides of the double-arch

\section{*E-mail address: Iclec_010@163.com}

ISSN: 1791-2377 @ 2020 School of Science, HHU. All rights reserved. doi:10.25103/jestr.132.14 tunnel, the composite skewness effect is produced. The vertical load distribution in the top arch of the double-arch tunnel is more complicated than that of the single-arch tunnel, so the distribution characteristics of the vertical load in the surrounding rock of the double-arch tunnel need further study.

\section{State of the art}

Reasonable assessing the load acting on the tunnel lining is an important part of the economic design. For the design of the tunnel, the overburden load is usually calculated using the Terzaghi formula or the soil column method, but some field measurements show that there is a big difference between the actual load and the calculation results [6]. To analyze the distribution characteristics of the vertical load in the surrounding rock of the tunnel, considering the oblique slip surface and lateral pressure coefficient, Cheng established the analytical expression of the vertical pressure on the circular tunnel based on Terzaghi's theoretical assumption [7]. For that the vertical pressure of the overburden on the deep buried tunnel calculated by the Terzaghi formula is higher than the measured value, Chen established a mechanical model considering the influence of stress transfer and analyzed the nonlinear distribution form of the vertical pressure with numerical simulation [8]. Song et al. believed that the surrounding rock in the pressure-arch transmits the load acting on the arch to the arch foot and the stable surrounding rock, and they proposed the calculation method for the load on the tunnel [9]. The pressure-arch 
Chunliu Li, Hao Liu, Shuangjun Xu, Jingtao Li and Chenhua Zhou/

Journal of Engineering Science and Technology Review 13 (2) (2020) 99 - 106

effect is a key factor that affects the stress redistribution in surrounding rock, the calculation of the load on the tunnel ignoring the arch effect will cause a large error. So, the vertical load calculation under the influence of load transferring in the pressure-arch zone still needs to be further optimized.

The pressure-arch is a manifestation of the resistance of the surrounding rock of the tunnel to uneven deformation and self-supporting effect. In response to the pressure-arch effect of the surrounding rock of the tunnel, Wang used infrared thermal imaging to experimentally study the evolution of stress field in the surrounding rock caused by the excavation of the single-arch tunnel and the double-arch tunnel [10-11]. Lee et al. used centrifuge models and numerical simulations to analyze the arch evolution in the surrounding rock of the single and parallel tunnels, and they used the arching indicators to determine the boundaries of active and passive arching areas [12]. According to the natural balance arch theory, the loose and collapsed rock mass under the pressure-arch is the pressure source of the surrounding rock. Wang et al. studied the prediction method of the tunnel collapse based on the pressure-arch effect and they found that the pressure-arch dividing criteria directly affect the determination of the collapse range [13]. Kong et al. based on the distribution characteristics of the vertical and horizontal stresses, they proposed the inner and outer boundaries and center-line of the arched area [14]. Chen et al. studied the development of stratum arches based on the stress redistribution after tunnel excavation, and they analyzed the vertical stress adjustment of the tunnel vault [15]. Ji et al. used a arch model to correct the vertical pressure of a deep buried tunnel, and they proposed a method for analyzing the stability of the tunnel excavation surface considering the effect of the three-dimensional arch [16]. Li et al. analyzed the pressure evolution characteristics of the surrounding rock of the double-arch tunnel after the step-by-step excavation considering the stress state, and they discussed the conversion and distribution characteristics of the load in the surrounding rock by numerical simulation [17-19].

After the tunnel excavation, the surrounding rock undergoes load migration during the process of resisting uneven deformation, and then the stress redistribution occurs, the arching effect occurs in the surrounding rock under the influence of the principle stress deflection. In previous studies, the calculation of the load in the surrounding rock was generally based on the assumption of evenly distributed vertical load, without considering the pressure-arch in the surrounding rock, which resulted in some differences between the theoretical calculation and the field measured values. After the double-arch tunnel being step-by-step excavated, the composite pressure-arch interacts on both sides of the tunnel. The bearing effect of the mid-partition wall directly affects the distribution characteristics of the pressure-arch. The vertical load pattern in the surrounding rocks under the skewness effect of the composite pressurearch needs further study.

The organizational structure of the rest of this study is as follows: Section 3 introduces the general situation of the double-arch tunnel and describes the research methods. Section 4 gives the analysis and discussions of the results. Section 5 summarizes the study and draws relevant conclusions.

\section{Methodology}

\subsection{Analysis of vertical load distribution characteristics} 3.1.1 Vertical load distribution of single tunnel

According to the balanced arch theory, the stress field in the surrounding rock is redistributed after the tunnel excavation. The natural balanced arch will be formed above the tunnel, the rock mass in the pressure-arch zone has self-supporting capacity. Due to the unloading behavior of the excavation, the overburden rock loses its support in the vertical direction, the vertical load is transferred to the surrounding rock on both sides, and the vertical load in the middle area of the pressure-arch span should be lower than the load on both sides.

Terzaghi considered the stress transmission in the surrounding rock of the tunnel and proposed that the overburden rock would slide along the slopes MN and PQ after the tunnel being excavated, and he considered that the vertical pressure on any horizontal plane in the loose body was uniformly distributed [7]. According to this assumption and calculation method, the equilibrium state of the differential body at the burial depth $Z$ can be analyzed. The mechanical model was constructed as shown in Fig. 1.

From the equilibrium conditions in the vertical direction

$2 B_{d} \gamma d z=2 B_{d}\left(\sigma_{v}+d \sigma_{v}\right)-2 B_{d} \sigma_{v}+2 c d z+2 \lambda \sigma_{v} d z \tan \varphi$

where, $\gamma$ is the density of the surrounding rocks, $\mathrm{kN} / \mathrm{m}^{3} . B_{d}$ is half of the pressure-arch span, m. $\varphi$ is the internal friction angle of the surrounding $\operatorname{rock}^{\circ} \cdot \lambda$ is the lateral pressure coefficient of the surrounding rock. $c$ is the cohesion of the surrounding rocks, MPa. $\sigma_{v}$ is the vertical stress of the unit, $\mathrm{MPa}$. and $z$ is the depth of the unit, $\mathrm{m}$.

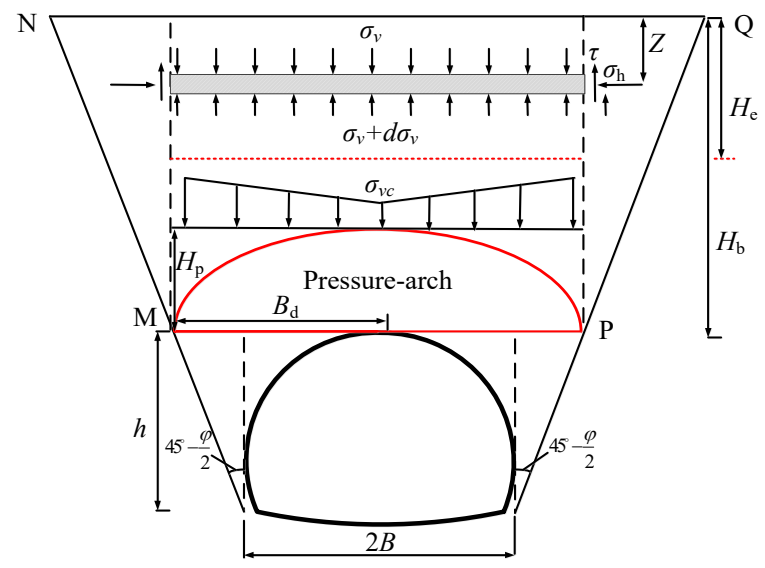

Fig. 1. Mechanical model of surrounding rock of single tunnel considering pressure-arch effect.

Eq. (2) can be obtained

$$
\frac{\mathrm{d} \sigma_{v}}{d z}=\gamma-\frac{c}{B_{d}}-\lambda \sigma_{v} \frac{\tan \varphi}{B_{d}}
$$

Considering the situation of no load on the surface, and according to the boundary conditions: $Z=0, \sigma_{v}=0$ and the geometric condition is:

$$
B_{d}=B+h \tan \left(45^{\circ}-\frac{\phi}{2}\right)
$$


where, $B$ is half of the tunnel span, $\mathrm{m}$.

Then the vertical stress $\sigma_{v}$ at any depth $Z$ can be expressed as follows.

$$
\sigma_{v}=\frac{\gamma\left[B+h \tan \left(45^{\circ}-\frac{\varphi}{2}\right)\right]-c}{\lambda \tan \varphi} \times\left(1-e^{\left.-\lambda \tan \varphi \frac{Z}{B+h \tan \left(45^{\circ}-\frac{\varphi}{2}\right)}\right)}\right.
$$

where, $\lambda$ is the lateral pressure coefficient of the surrounding rock.

According to Fig. 1, if the critical buried depth of the distribution area of the vertical load outside the pressurearch affected area is $H_{\mathrm{e}}$, and the vertical load of the rock mass occurs transformation with different degrees in the pressure-arch effect area with a depth of $Z \geqslant H_{e}$, that is, the vertical stress is transformed into the deflected maximum principal stress $\sigma_{1}$ in the arch path, and the maximum principal stress $\sigma_{1}$ is greater than the vertical stress $\gamma Z$ of the surrounding rock. If $x$ is the horizontal distance between the particle and the center of the tunnel, then the redistribution of vertical stress $\sigma_{v c}(x)$ at different horizontal positions under the fixed depth can be simplified as the trapezoidal distribution law. The mid-span position of the tunnel is the center of the unloading area for excavation, and the vertical stress at this position is directly transformed into the horizontal principle stress, so the redistribution of the vertical stress $\sigma_{v c}(0)$ at the center of the tunnel $(x=0)$ can be expressed as:

$$
\sigma_{v c}(0)=\gamma Z-\left(\sigma_{1}-\lambda_{0} \gamma Z\right)
$$

where, $\sigma_{1}$ is the horizontal principal stress at the mid-span of the tunnel at the buried depth $Z, \mathrm{MPa} . \lambda_{0}$ is the lateral pressure coefficient of the stress state of the surrounding rock.

For the overburden in the area affected by the pressurearch effect, the vertical stress $\sigma_{v c}\left(B_{d}\right)$ at the left and right boundary positions of the pressure-arch $\left(x=B_{\mathrm{d}}\right)$ is calculated according to Terzaghi theory, that is, $\sigma_{v c}\left(B_{d}\right)=\sigma_{v}$. At the same time, considering the influence of the vertical load transferring in the surrounding rock under the influence of pressure-arch effect, the vertical stress of the overburden at different horizontal positions is calculated by reducing method under the condition of the determined buried depth $Z$, and it can be seen that the vertical stress $\sigma_{v c}$ in the area of pressure-arch effect can be expressed as follows.

$\sigma_{v c}=\sigma_{v c}(0)+\frac{\left(\sigma_{v}-\sigma_{v c}(0)\right) x}{B_{d}}$

Substituting Eq. (5) into Eq. (6), then Eq. (4) can be obtained.

$$
\sigma_{v c}=\gamma Z+\lambda_{0} \gamma Z-\sigma_{1}+\left(\sigma_{v}+\sigma_{1}-\gamma Z-\lambda_{0} \gamma Z\right) \frac{x}{B+h \tan \left(45^{\circ}-\frac{\varphi}{2}\right)}
$$

Eq. (7) can be used to calculate and determine the vertical stress distribution at different horizontal positions of the pressure-arch zone under the condition of the buried depth $Z$.

\subsubsection{Vertical load distribution of double-arch tunnel}

As can be seen in Fig. 2, compared with the single tunnel, the stress disturbance range in the surrounding rock is larger after the excavation of the double-arched tunnel, and the excavation sequence of the left, right tunnels and the strength of the mid-partition wall affect the overall stability, stress distribution characteristics of the surrounding rock structure, so different construction effects and bearing capacities of the mid-partition wall should be considered [4].

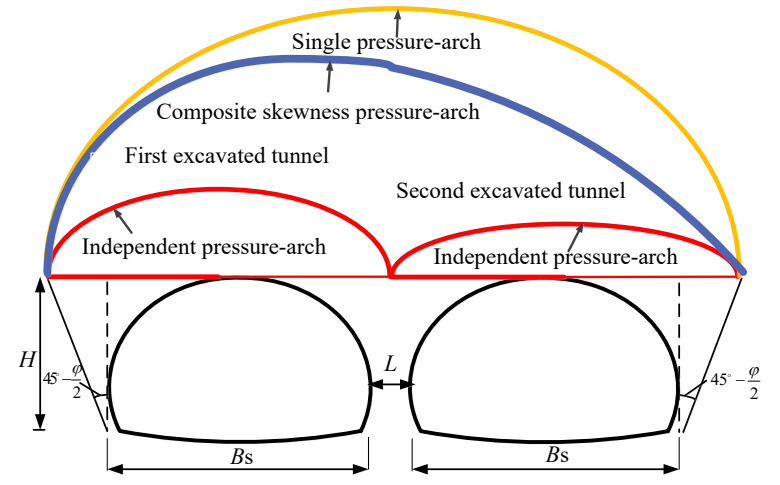

Fig. 2. Mechanical model of surrounding rock of double-arch tunnel considering pressure-arch effect.

It can be seen from Fig. 3, according to the pressure-arch theory, the stress state in the surrounding rock of the doublearch tunnel can be discussed in three cases as follows:

(1) If the surrounding rock on the top of the midpartition wall is not deformed, the mid-partition wall being supported and closely adhere to the surrounding rock, the mid-partition wall fully exerts the bearing capacity. The mid-partition wall shows the same supporting effect as the surrounding rock of the tunnel side wall. The surrounding rock on one side of the tunnel can form an independent pressure-arch, on both sides of the double-arch tunnel will produce the double independent pressure-arch effect.

(2) The mid-partition wall is elastically deformed and in close contacted with the surrounding rock. The mid-partition wall bears part of the load across the overlying rock, the pressure-arch of the surrounding rock on both sides of the tunnel are partially merged above the mid-partition wall. A composite pressure-arch is formed, but the first excavation disturbance range is greater than the latter in the surrounding rock, the skewness effect of the pressure-arch exists.

(3) For conditions where the mid-partition wall is too convergent or the top backfill is not dense, the mid-partition wall fails to perform the bearing function. The overburden of the double-arch tunnel can be regarded as having no central support and can be treated as a large-span single-arch tunnel. The surrounding rock of the double-arch tunnel vault can only form a whole pressure-arch.

According to Fig. 3, the vertical stress of the surrounding rock in the pressure-arch effect area can be calculated. The vertical stress in the effect zone can be considered according to the stress state of the surrounding rock of the single-arch tunnel: When two independent pressure-arches are formed in the surrounding rock over the double-arch tunnel, the vertical stress in the arch effect zone can be considered according to the single-arch tunnel. that is, Eq. (7) is used to calculate the vertical stress $\sigma_{v c}$. In the case where the midpartition wall cannot be effectively carried, the double-arch tunnel can be regarded as a large-span cave with no support 
Chunliu Li, Hao Liu, Shuangjun Xu, Jingtao Li and Chenhua Zhou/

Journal of Engineering Science and Technology Review 13 (2) (2020) 99 - 106

in the middle. The stress state of the surrounding rock of the vault needs to be considered a single pressure-arch condition with a double span.

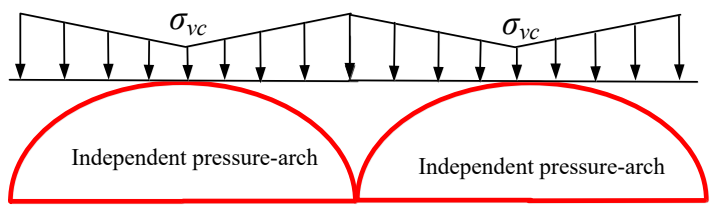

(a) Double independent pressure-arch

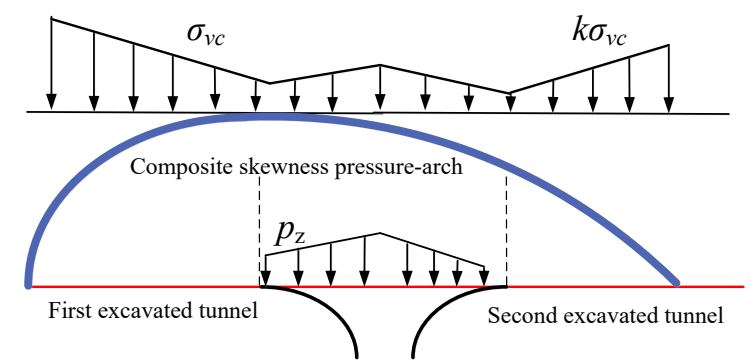

(b) Composite skewness pressure-arch

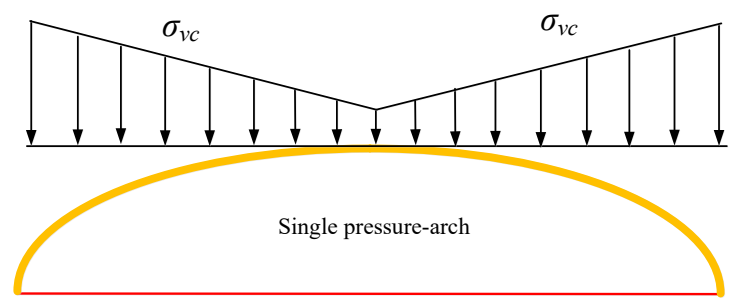

(c) Single pressure-arch

Fig. 3. Vertical stress distribution characteristics under three typical pressure-arch forms

If $x_{\mathrm{s}}$ is the horizontal distance between the calculation point and the center point of the mid-partition wall, the vertical stress $\sigma_{v d}$ at the left and right boundary positions of the pressure-arch can be calculated according to Terzaghi theory, that is:

$x_{s}=B_{s}+\frac{L}{2}+H \tan \left(45^{\circ}-\frac{\varphi}{2}\right)$

where, $B_{s}$ is the width of the left or the right tunnel, m. $L$ is the width of the mid-partition wall, $\mathrm{m}$.

$\sigma_{v \mathrm{~d}}=\frac{\gamma\left[B_{s}+\frac{L}{2}+H \tan \left(45^{\circ}-\frac{\varphi}{2}\right)\right]-c}{\lambda \tan \varphi} \times\left(1-e^{\left.-\lambda \tan \varphi \frac{Z}{B_{s}+\frac{L}{2}+H \tan \left(45^{\circ}-\frac{\varphi}{2}\right)}\right)}\right.$

where, $H$ is the height of the double-arch tunnel, $\mathrm{m}$.

Considering the pressure-arch effect, the vertical stress of overlying rock at different horizontal positions under the condition of determining the depth $Z$ is reducing calculated, Combined Eq. (9), the vertical stress $\sigma_{v c}$ of a single integral pressure-arch effect zone can be expressed as:

$$
\sigma_{v c}=\gamma Z+\lambda_{0} \gamma Z-\sigma_{1}+\left(\sigma_{v d}+\sigma_{1}-\gamma Z-\lambda_{0} \gamma Z\right) \frac{x_{s}}{B_{s}+0.5 L+H \tan \left(45^{\circ}-\frac{\varphi}{2}\right)}
$$

If the skewness pressure-arch in the surrounding rock of the double-arch tunnel forms, the vertical load $p_{\mathrm{z}}$ of the midpartition wall and the excavation sequence of the left and right tunnels need to be considered, while the $p_{\mathrm{z}}$ of load borne by the mid-partition wall depends on the compressive strength of the wall concrete and rock mass of the wall roof [4].

For the first excavated tunnel, the calculation of the vertical stress in the pressure-arch effect area should also be solved in sections. When the horizontal distance between the calculated point and the center point of the mid-partition wall is $x_{\mathrm{s}} \geq 0.5\left(B_{\mathrm{s}}+L\right)$, the vertical stress conforms to the expression of Eq. (4). For the overburden in the area where the mid-partition wall connects, the horizontal distance $x_{\mathrm{s}}<0.5\left(B_{\mathrm{s}}+L\right)$, and the vertical stress $\sigma_{v k}$ at the boundary position of the area $\left(x_{\mathrm{s}}=0\right)$ should be determined according to the bearing capacity of the mid-partition wall. Eq. (7) can be used to calculate the vertical stress where the partition wall is connected. Then, the skewness effect should be taken into account in the bearing state of surrounding rock of the excavated tunnel, and the reduction coefficient $k$ is used to calculate the vertical stress.

\subsection{Numerical simulation analysis}

\subsubsection{Computational model}

Taking the typical section of the double-arch tunnel of Huangshan-Quzhou highway in Zhejiang Province, China, as an example, the designed excavation sizes of the tunnel are about $11.60 \mathrm{~m}$ wide and $8.80 \mathrm{~m}$ high, by step-by-step excavation. To compare the difference of the pressure-arch effect, the single-arch tunnel and double-arch tunnel were adopted to conduct the excavation schemes. The threedimension computational model of the double-arch tunnel was built by using ANSYS and FLAC ${ }^{3 \mathrm{D}}$ technique as shown in Fig. 4. The sizes of the model are length $\times$ width $\times$ height $=70 \mathrm{~m} \times 4 \mathrm{~m} \times 40 \mathrm{~m}$, and the model is divided into 9536 elements.

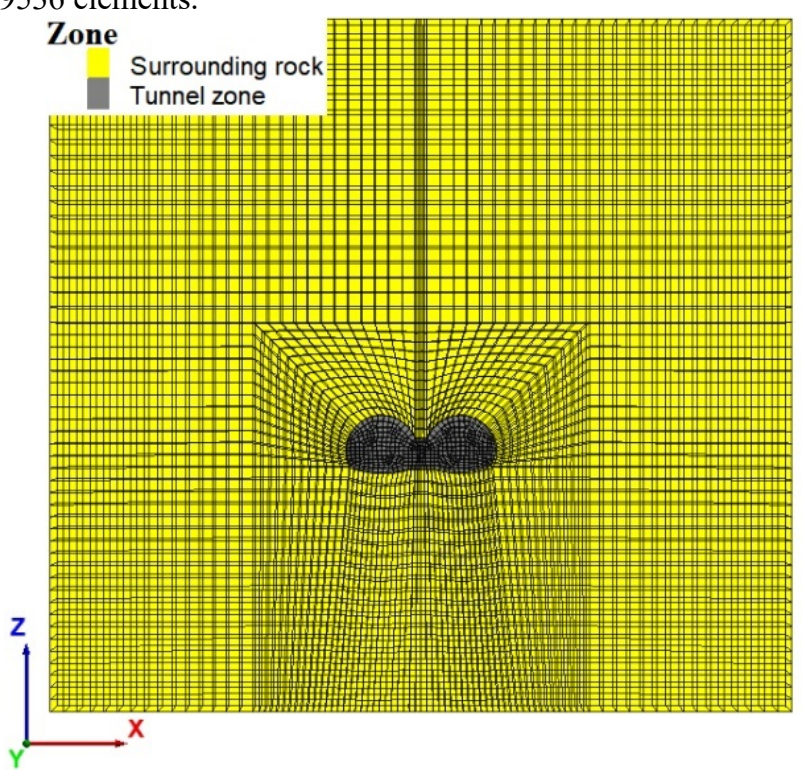

Fig. 4. The computational model and its meshes.

\subsubsection{Boundary conditions and calculation parameters}

The lateral sides of the calculation model were restricted the horizontal movement and the bottom was fixed. The upper surface of the model was the load boundary. The uniform loading was applied to simulate the self-weight of the overlying rock layer. It is assumed that the surrounding rock failure of the double-arch tunnel meets the Mohr-Coulomb strength criterion and the tunnel is in the stress state of 
hydro-static, that is, the lateral pressure coefficient $\lambda=1.0$. The physical and mechanical parameters of the surrounding rock are selected according to the recommended values of the China code, as listed in Table 1.

The Class III surrounding rock is taken as a case for calculation in this section. Since the mid-partition wall in this study only produces elastic deformation and which is in close contact with the surrounding rock. the density and elastic modulus of the mid-partition wall were assumed to be the same as that of the surrounding rock.

Table 1. Materials parameters of the surrounding rock.

\begin{tabular}{c|c|c|c|c|c}
\hline $\begin{array}{c}\text { Density } \\
\left(\mathbf{g} / \mathbf{c m}^{3} \mathbf{)}\right.\end{array}$ & $\begin{array}{c}\text { Elasticity } \\
\text { Modulus } \\
\text { (GPa) }\end{array}$ & $\begin{array}{c}\text { Poisson's } \\
\text { ratio }\end{array}$ & $\begin{array}{c}\text { Cohesive } \\
\text { strength } \\
(\mathbf{M P a})\end{array}$ & $\left.\begin{array}{c}\text { Internal } \\
\text { friction } \\
\text { angle }\end{array} \mathbf{(}^{\circ}\right)$ & $\begin{array}{c}\text { Tension } \\
\text { strength } \\
(\mathbf{M P a})\end{array}$ \\
\hline 26 & 20 & 0.25 & 1.5 & 42 & 0.5 \\
\hline
\end{tabular}

\subsubsection{Pressure-arch parameters}

To characterize the pressure arching effect of the surrounding rock and the characteristics of vertical load variation, the arching index $k$ and the vertical stress variation rate $r$ are defined. Combined with fish language programming in FLAC3D, these indicators can be obtained in the post-processing display and monitored to analyze the evolution characteristics of the stress field of the surrounding rock after the tunnel being excavated. The expressions of the arching index and the vertical stress variation rate are as follows.

$$
k=\frac{\sigma_{1}-\sigma_{0}}{\sigma_{0}}
$$

where, $\sigma_{1}$ is the maximum principal stress in the surrounding rock after excavation, MPa. $\sigma_{0}$ is the maximum principal stress in the surrounding rock before excavation, $\mathrm{MPa}$.

According to Eq. (11), when $k>0$, it is the range of the pressure-arch; when $-1<k<0$, it is in the compressive stress reduction zone; when $k<-1$, it is in the tensile stress zone.

In this study, Eq. (12) can be simplified as follows.

$$
r=\frac{\sigma_{v}-\gamma h}{\gamma h}
$$

where, $\gamma$ is the density of the overburden rock, $\mathrm{kN} / \mathrm{m}^{3} . \quad h$ is the buried depth of the tunnel, m. $\sigma_{\mathrm{v}}$ is the maximum principal stress in the surrounding rock after excavation, $\mathrm{MPa}$.

\section{Results and Discussion}

\subsection{Distribution characteristics of pressure-arch and vertical load of single-arch tunnel}

As shown in Fig. 5(a), after the tunnel being excavated, the pressure-arch was formed a closed arch ring. The internal boundary of the pressure-arch coincided with the excavation boundary of the tunnel. The arching index of the surrounding rock near the inner boundary of the pressurearch was higher than the arch area, and the arching index decreased gradually from the inner boundary outward in the radial direction. Under the influence of the arching effect, the vertical load of the roof overburden was transferred to the surrounding rock of the arch waist and arch foot, thus causing the loosening and unloading of the vertical load of the roof overburden along the arch path.

It can be seen from Fig. 5(b), there was an obvious vertical stress reduction zone in the overburden of the tunnel and the shape of the inverted trapezoid outside the arch was consistent with the unloading sliding body characteristics in Terzaghi's theory of loose earth pressure. The unloading degree was the largest at the excavation boundary of the tunnel. The minimum vertical stress change rate was located at the mid-span of the tunnel. The vertical load of the overhanging rock in the unloading loose zone transfered to the surrounding rock on both sides, and the vertical stress rising zone was formed in the surrounding rock at the arch waist and foot.

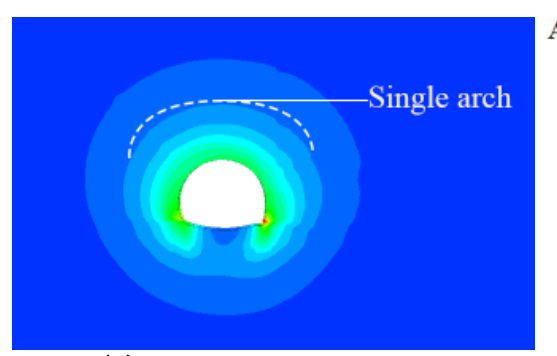
Arching index
$1.9754 \mathrm{E}+00$ 1.8000E+00 1.6000E +00 $1.4000 \mathrm{E}+00$ $1.2000 \mathrm{E}+00$ 1.0000E+00 $8.0000 \mathrm{E}-01$ $6.0000 \mathrm{E}-01$ 4.0000E-01 $2.0000 \mathrm{E}-01$ $0.0000 E+00$ $-3.5454 E-03$

(a) Arching effect in the surrounding rock

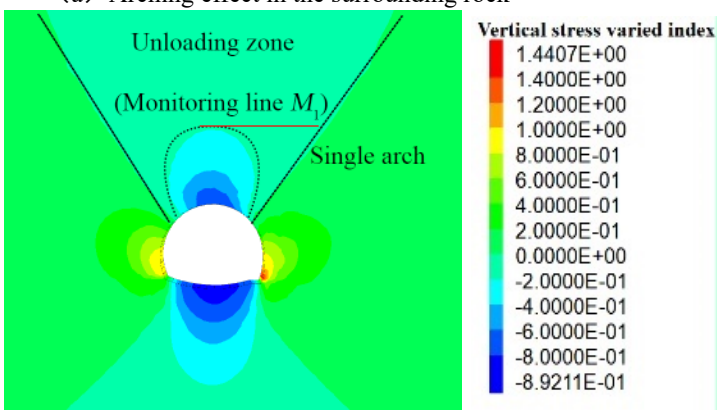

(b) Distribution of vertical stress in surrounding rock

Fig. 5. Arching effect and vertical stress distribution in the surrounding rock of single-arch tunnel.

According to the monitoring data of the horizontal survey line $\mathrm{M}_{1}$, the vertical stress distribution of the arch top are shown in Fig. 6(a). After the tunnel being excavated, the vertical stress was transformed into the non-uniformly distributed compressive stress. The vertical stress decreased gradually from the side walls of the tunnel to the mid-span position, and the vertical stress in the surrounding rock on both sides of the tunnel was higher than the original rock stress. It indicated that the vertical load transfer of the overburden caused by the excavation unloading.

As shown in Fig. 6(b), the peak value of the arching index of the overburden rock was located at the middle of the tunnel. As the distance from the pressure-arch top increased, the arching index changed from a symmetrical parabolic distribution to a uniform linear distribution.

The vertical stress of the monitoring data at $10 \mathrm{~m}$ and 20 $\mathrm{m}$ from the pressure-arch vault are shown in Fig. 6(c). Under the influence of the pressure-arch, the vertical stress of the overburden rock on both sides of the tunnel was linearly decreasing. The distance of the arch effect zone increased, and the vertical stress of the overlying rock outside the pressure-arch gradually decreased from a linear decrease to a uniform distribution. This showed that the pressure-arch caused the self-supporting effect of the overlying rock. The vertical load of the rock mass was transferred from the span to the two sides along the arching path. The rock mass in the 
Chunliu Li, Hao Liu, Shuangjun Xu, Jingtao Li and Chenhua Zhou/

Journal of Engineering Science and Technology Review 13 (2) (2020) 99 - 106

arching area born the upper rock mass load, so that the vertical stress above the pressure-arch remained uniform.

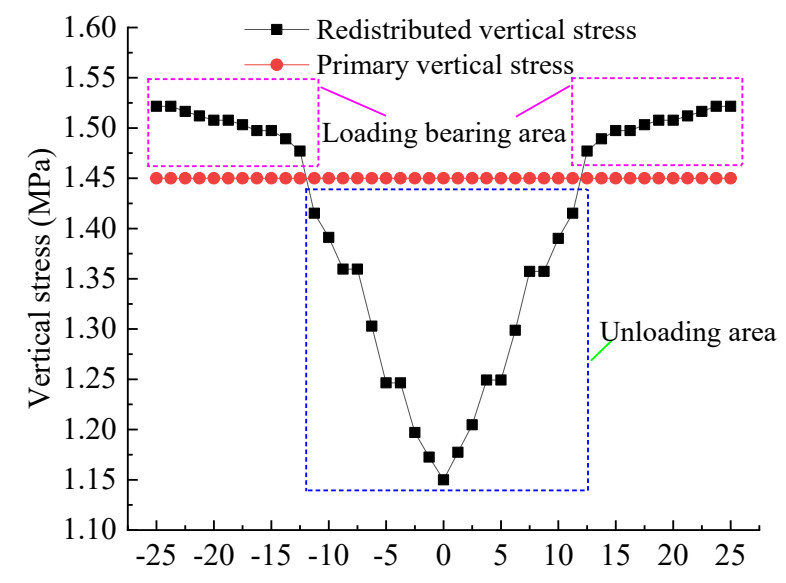

Distance from the tunnel center $(\mathrm{m})$

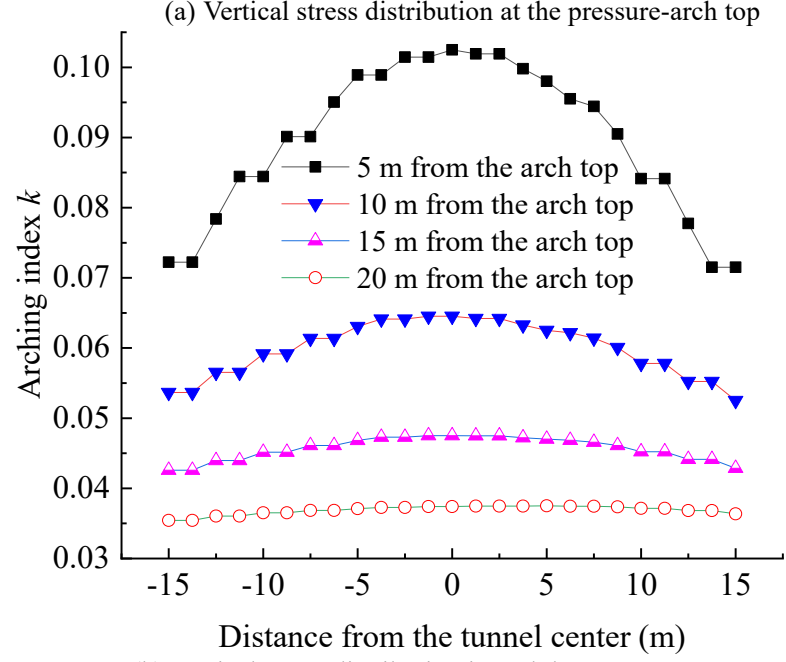

(b) Vertical stress distribution in arch loose zone

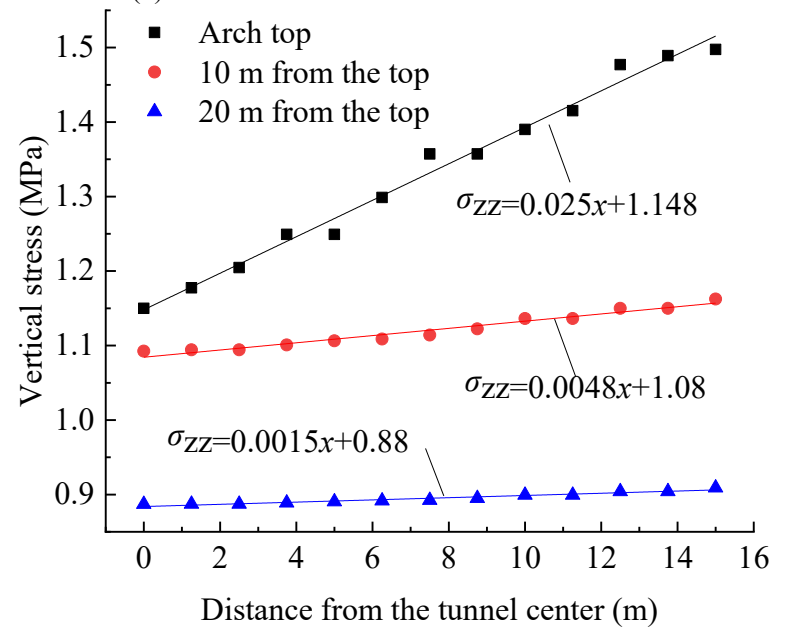

(c) Vertical stress variation outside pressure-arch

Fig. 6. Variation characteristics of vertical stress in surroundingrock of single-arch tunnel.

\subsection{Distribution characteristics of skewness pressure-} arch and vertical load of double-arch tunnel

The step-by-step method was used to excavate the doublearch tunnel. As shown in Fig. 7, to compare the excavation sequence effect of the tunnel, one scheme was that the left tunnel was first excavated and then the right tunnel, another one was that the right tunnel was first excavated and then the left tunnel. The arching index of the surrounding rock was used to analyze the distribution characteristics of pressurearch in the surrounding rock of the double-arch tunnel.

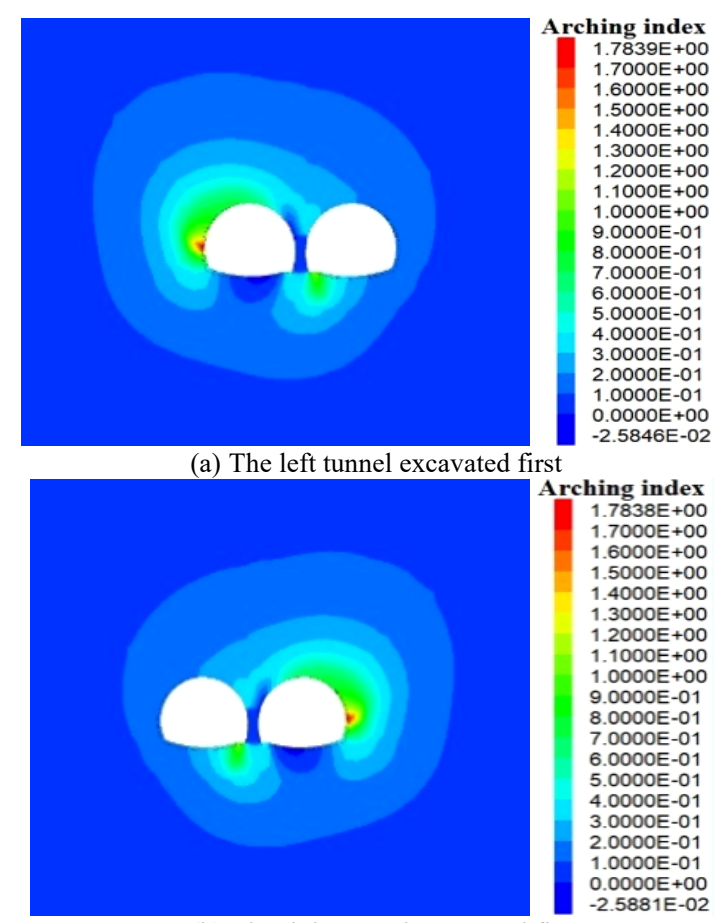

(b) The right tunnel excavated first

Fig. 7. Distribution characteristics of skewness pressure-arch in surrounding rock of double-arch tunnel.

Compared with the single-arch tunnel, the unloading range of the double-arch tunnel was increased. It can be seen from Fig. 7, after the double-arched tunnel being excavated, there was a obviously skewness effect of the pressure-arch in the surrounding rock. There were two large and small pressure-arch circles in the surrounding rock on the left and right of the tunnel. The arching index of the surrounding rock in the near excavation area was higher than that in the far area. The inner boundary of the pressure-arch was distributed along the tunnel excavation boundary and the arching index gradually decreased along the radial direction of the tunnel. The pressure-arch at the arch roof and the arch waist in the surrounding rock was larger, and the peak value of arching index in the large arch circle in the surrounding rock was higher than that in the later excavation. This showed that during the excavation of the double-arch tunnel, the larger pressure-arch of the first excavated tunnel was the main bearing area of the double-arch tunnel.

Taking the left tunnel excavation first as an example, the monitoring data of the arching index $k$ at different levels of the tunnel was shown in Fig. 8. There was a skewness distribution of the arching index of the double-arch tunnel. The skewness parabola distribution of the arching index of the first excavated tunnel was shown, and the peak value was located at the mid-span of the first excavated tunnel. The arching index in the surrounding rock of the excavated tunnel showed a decreasing curve distribution, and the concentration of the main stress in the surrounding rock of the excavation area was higher than that of other areas. As the distance from the tunnel vault increased, the arching index gradually decreased, and the arching index of the double-arch tunnel formed a parabolic parabola to a the horizontal straight line. 
Chunliu Li, Hao Liu, Shuangjun Xu, Jingtao Li and Chenhua Zhou/

Journal of Engineering Science and Technology Review 13 (2) (2020) 99 - 106

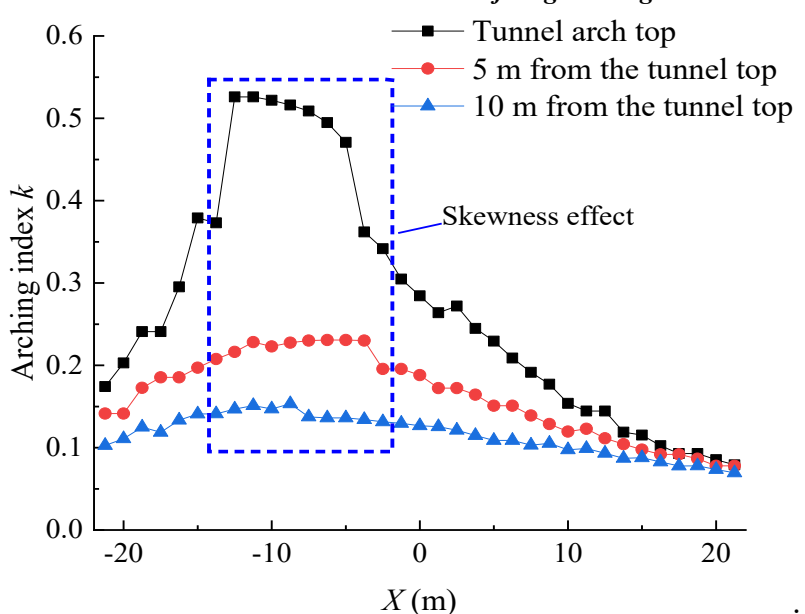

Fig. 8. Distribution characteristics of arching index in case of excavating left tunnel first.

According to the monitoring data of the horizontal line of the tangent position of the arch top of the double-arch tunnel, as shown in Fig. 9(a), the vertical stress at the tunnel top under the influence of the skewness pressure-arch was asymmetrical. The vertical stress in the surrounding rock of the first excavated tunnel was higher than that in the later excavated tunnel. This indicated that the surrounding rock of the first excavated tunnel played the main bearing role during the excavation of the double-arch tunnel. The vertical stress at the top of the mid-partition wall was parabolic, and the peak vertical stress at the center of the partition was significantly lower than the vertical stress at the side wall.

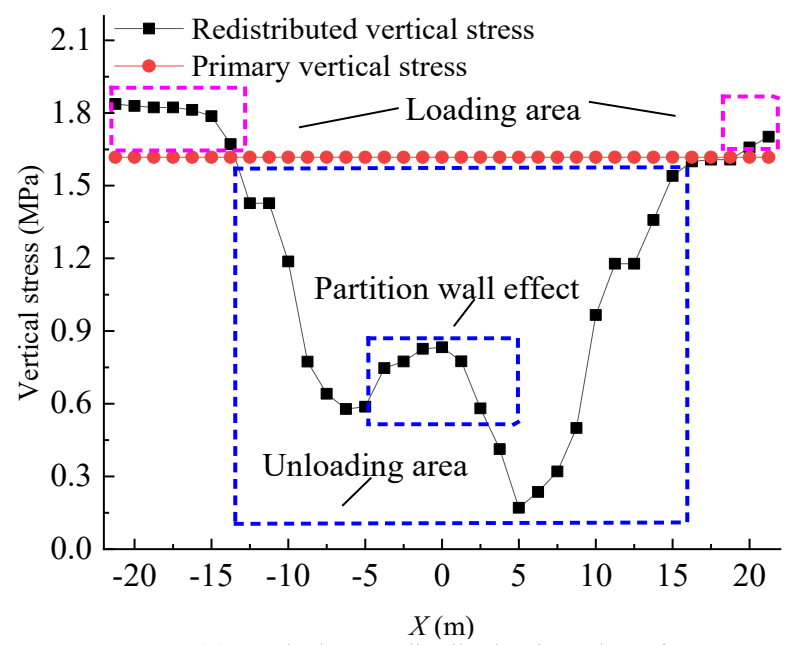

(a) Vertical stress distribution in arch roof

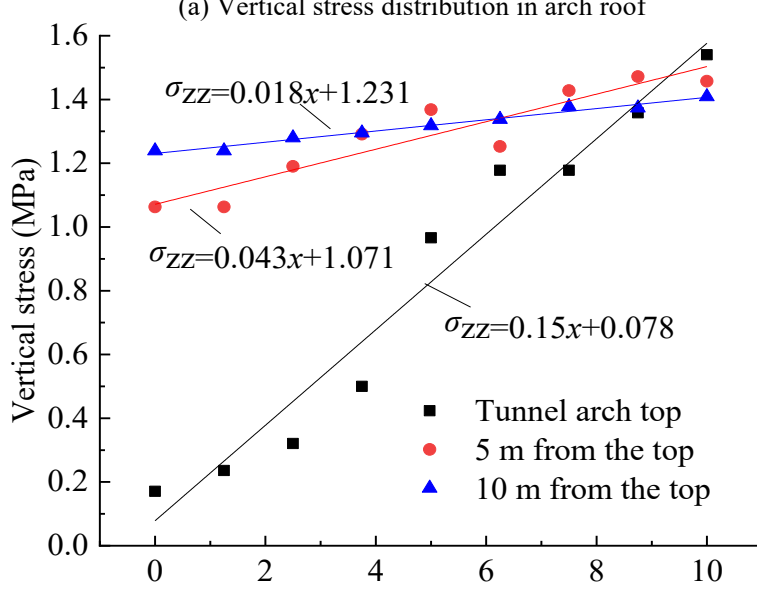

Distance from the partition wall center $(\mathrm{m})$ (b) Vertical stress variation affected by the arch effect
Fig. 9. Distribution characteristics of vertical stress affected by pressure-arch.

Taking the excavation area on the right tunnel as the research object, as shown in Fig. 9(b), the vertical stress gradually decreased from the tunnel side wall to the midspan position. As the distance from the vault increased, the vertical stress changed under the influence of the pressurearch. The rate gradually decreased, and the vertical stress away from the arch effect zone gradually changed to a uniform distribution.

\section{Conclusions}

To investigate the load transferring rule of the surrounding rock of the double-arch tunnel, based on the highway tunnel of in Zhejiang province, China, the distribution characteristics of pressure-arch and vertical load of the surrounding rock were analyzed by mechanical model and numerical simulation, some conclusions are as following:

(1) There are two typical distribution characteristics of the vertical stress of the single-arch tunnel after excavation. The arch top in the near excavation area is affected by the pressure-arch, and the vertical load is transferred from the mid-span to both sides of the surrounding rock along the arching path, while the vertical stress in the pressure-arch effect area decreases from the boundary to the mid-span in the horizontal direction. Due to the support and load bearing effect in the pressure-arch zone, the vertical stress outside the pressure-arch zone gradually recovered from linear declining to uniform distribution as the distance from the pressure-arch zone increased, and the calculation of uniform distributed vertical stress was applicable to the Terzaghi theoretical formula.

(2) After the excavation of the double-arch tunnel, the skewness pressure-arch exists in the surrounding rock, the large and small pressure-arch ring is formed in the surrounding rock of the left and right tunnel, and the surrounding rock of the first excavated tunnel is the main bearing area. The arching index in the near excavation area is higher than that in the far area. The arching index gradually decreases along the radial direction of the tunnel. The arching index of the first excavated tunnel is approximately parabolic, and the peak of the arching index is located at the mid-span position of the first excavated tunnel. The arching index of the later excavated tunnel shows decreased distribution. The arching index of the double-arch tunnel changes from a skewed parabola to a horizontal straight line along vertical direction.

(3) The vertical stress of the tunnel vault is distributed asymmetrically under the influence of the skewness pressure-arch. The vertical stress in the first excavated tunnel is higher than that in the later excavated tunnel, and the vertical stress gradually decreases from the sidewall to the mid-partition wall along the horizontal direction. The vertical stress near the partition wall area exists composite loading and unloading effect and shows parabolic distribution. The peak vertical stress at the center of the partition is significantly lower than that at the side wall, the vertical stress gradually transforms to a uniform distribution with the distance with the increase of the distance from the excavation area.

The load transmission in the surrounding rock is the key mechanical problem in tunnel engineering, by analyzing the arching characteristics of the major principle stress in the surrounding rock, the variation of pressure-arch was 
Chunliu Li, Hao Liu, Shuangjun Xu, Jingtao Li and Chenhua Zhou/

Journal of Engineering Science and Technology Review 13 (2) (2020) 99 - 106

revealed preliminarily. On the basis of identifying skewness effect of nonuniform load during tunnel excavation, the long term adjustment of the surrounding rock load still needs monitoring, especially the additional load acting on the first excavated tunnel. The re-transferring of extra stress from the large pressure-arch to the small one is the future research work.

\section{Acknowledgments}

This work was financially supported by the Scientific Research Fund of Hebei Normal University of Science and
Technology, Science and Technology Research Project of Hebei Higher Education Institutions of China (QN2017333), and the National Natural Science Foundation of China (51474188).

This is an Open Access article distributed under the terms of the Creative Commons Attribution License

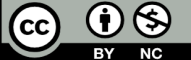

\section{References}

1. Hwang, J. H., Kikumoto, M., Kishida, K., Kimuraa, M. "Dynamic stability of multi-arch culvert tunnel using 3-D FEM". Tunnelling and Underground Space Technology, 21(3-4), 2006, pp. 384.

2. Yan, Q. X., Zhang, C., Lin, G., Wang, B. "Field monitoring of deformations and internal forces of surrounding rocks and lining structures in the construction of the Gangkou double-arched tunnela case study". Applied Sciences, 7(2), 2017, pp. 169-189.

3. Min, B., Zhang, X., Zhang, C., Gong, Y. P., Yuan, T. F. "Mechanical behavior of double-arch tunnels under the effect of voids on the top of the middle wall". Symmetry, 10(12), 2018, pp. 703-723.

4. Li, H. B., Guo, X. H. "Research on calculation methods of earth pressure on muti-arch tunnel for highway". Rock and Soil Mechanics, 30(11), 2009, pp. 3430-3434.

5. Dancygier, A. N., Karinski, Y. S., Chacha, A. "A model to assess the response of an arched roof of a lined tunnel". Tunnelling and Underground Space Technology, 56, 2016, pp. 211-225.

6. Mashimo, H., Ishimura, T. "Evaluation of the load on shield tunnel lining in gravel". Tunnelling and Underground Space Technology, 18(2), 2003, pp.233-241.

7. Cheng X. H. "Earth pressure on circular tunnel lining in dense sand and hard clay". Chinese Journal of Rock Mechanics and Engineering, 33(4), 2014, pp. 857-864.

8. Chen, K. H., Peng, F. L. "An improved method to calculate the vertical earth pressure for deep shield tunnel in Shanghai soil layers". Tunnelling and Underground Space Technology, 75, 2018, pp. $43-66$.

9. Song Y. X., Zhang, Y. H., Liu, Y. "Study on surrounding rock pressure based on pressure arch theory". Journal of Disaster Prevention and Reduction, 33(2), 2017, pp. 45-51.

10. Wang, S .R., Li, D. J., Li, C. L., Zhang, C. G., Zhang, Y. B. "Thermal radiation characteristics of stress evolution of a circular tunnel excavation under different confining pressures". Tunnelling and Underground Space Technology, 78, 2018, pp. 76-83.
11. Wang, S. R., Li, C. L., Li, D. J., Zhang, Y. B., Hagan, P. "Skewed pressure characteristics induced by step-by-step excavation of double-arch tunnel based on infrared thermography". Tehnicki Vjesnik-Technical Gazette, 23(3), 2016, pp. 827-833.

12. Lee, C. J., Wu, B. R., Chen, H. T., Chiang, K. H. "Tunnel stability and arching effects during tunneling in soft clayey soil".Tunnelling and Underground Space Technology, 21(2), 2006, pp. 119-132.

13. Wang, Y. C., Jing, H. W., Zhang, Q., Luo, N., Yin, X. "Prediction of collapse scope of deep-buried tunnels using pressure arch theory". Mathematical Problems in Engineering, 2016(3-4), 2016, pp. $1-10$.

14. Kong, X. X., Liu, Q. S., Zhang, Q. B., Wu, Y. X., Zhao, J. “A method to estimate the pressure arch formation above underground excavation in rock mass". Tunnelling and Underground Space Technology, 71, 2018, pp. 382-390.

15. Chen, C. N., Huang, W. Y., Tseng, C. T. "Stress redistribution and ground arch development during tunneling". Tunnelling and Underground Space Technology, 26(1), 2011, pp. 228-235.

16. Ji, X. B., Ni, P. P., Barla, M., Zhao, W., Mei, G. X. "Earth pressure on shield excavation face for pipe jacking considering arching effect”. Tunnelling and Underground Space Technology, 72, 2018, pp. 17-27.

17. Li, C. L., Wang, S. R.,Wang, Y. G., Cui, F., Yang, F. "Skewed pressure characteristics of equivalent load in double-arch tunnel". Journal of Engineering and Technological Sciences, 48(3), 2016, pp. $345-358$

18. Wang, S. R., Li, C. L., Wang, Y. G., Zou, Z. S. "Evolution characteristics analysis of pressure-arch in double-arch tunnel". Tehnicki Vjesnik- Technical Gazette, 23(1), 2016, pp. 181-189.

19. Wang, S. R., Wang, Y. G., Li, C. L., Zou, Z. S., Cui, F. "Evolution characteristics analysis of pressure-arch of a highway tunnel under different stress conditions". Journal of Engineering Science and Technology Review, 9(3), 2016, pp. 99-105. 